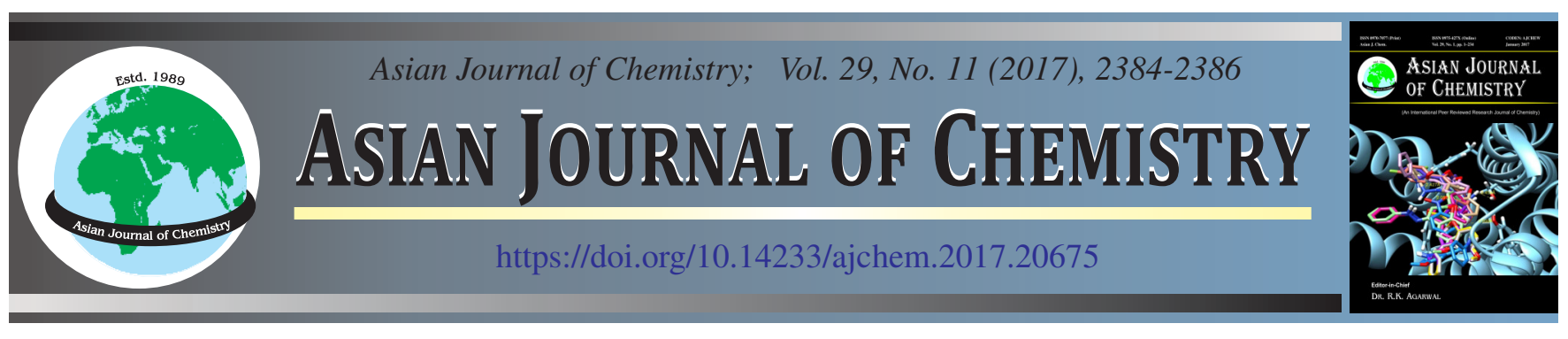

\title{
Fast Determination of Naringin and Hesperidin in Natural and Commercial Citrus Juices by HPLC Method
}

\author{
E. BÜYÜKTUNCEL
}

Department of Analytical Chemistry, Faculty of Pharmacy, Inönü University, Malatya, Turkey

Corresponding author: E-mail: saliha.buyuktuncel@inonu.edu.tr

\begin{abstract}
A reversed-phase high performance chromatographic method for simultaneous determination of naringin and hesperidin in natural and commercial citrus juices was developed. The separation was achieved on Zorbax Eclipse XDB C18 column $(4.6 \mathrm{~mm} \times 250 \mathrm{~mm}, 5 \mu \mathrm{m})$ using a acetonitrile:water:formic acid (21:78.8:0.2) solution at $\mathrm{pH} 2.5$ as a mobile phase under isocratic conditions. Analysis was run at a flow rate of $1 \mathrm{~mL} \mathrm{~min}^{-1}$ with a $15 \mathrm{~min}$ total run time at room temperature. The detection wavelength was set at $280 \mathrm{~nm}$. Linearity of calibration, accuracy, precision were examined as parts of the method validation. The optimized method was applied to analysis of natural and commercial citrus juices. Commercial fruit juices contained lower amount of naringin and hesperidin compared with natural fruit juices.
\end{abstract}

Keywords: Naringin and hesperidin, Citrus juices, HPLC.

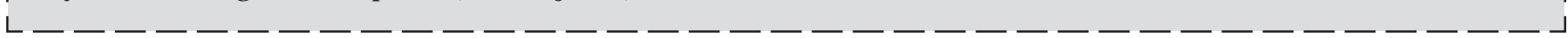

\section{INTRODUCTION}

Citrus fruits are good source of flavonoids. Citrus flavonoids are generally classified into two groups, flavanone glycosides (naringin, hesperidin, neohesperidin, etc.) and polymethoxylated flavones (nobiletin, sinensetin, tangeretin, etc.) [1]. They act as antioxidant and scavenge free radicals. They have been reported to have anti-inflammatory, antiulcer and antiallergenic properties [2]. Several epidemiological studies show that there is an inverse effect between intake of flavonoids and the risk of hypertension, cardiovascular diseases, different types of cancer and metabolic syndrome [3-5].

There are many different methods used for the analysis of flavonoids in sweet orange peel [6], citrus fruits [1,4,7], pharmaceutical formulations [2], orange juice and orange wine [8], grapefruit [9-11], in food supplements [12] including high performance liquid chromatography, capillary electrophoresis with different detectors, UV-visible, diode array detection (DAD), mass spectrometry and electrochemical detectors.

This paper represents fast method for determination of naringin and hesperidin in commercial and natural citrus fruit juices by HPLC with simple sample preparation. It is important to compare the amount of naringin and hesperidin between commercial and natural fruit juices.

\section{EXPERIMENTAL}

Standard substances of naringin, hesperidin and dimethyl sulfoxide were purchased from Sigma-Aldrich (St. Louis, MO,
USA). All the solvents and reagents that are used in this study were HPLC or analytical grade. Water was purified (18 M $\Omega$ $\mathrm{cm}^{-1}$ quality) from New Human Power I (Korea).

Stock standard solution of naringin was dissolved in methanol to a concentration of $1 \mathrm{mg} \mathrm{mL}^{-1}$. Stock standard solution of hesperidin was dissolved in $25 \mathrm{mM}$ DMSO in ultrapure to a concentration of $1 \mathrm{mg} \mathrm{mL}^{-1}$. They were stored in darkness at $-20{ }^{\circ} \mathrm{C}$ until analyzed. The calibration curves were prepared by diluting the stock solution in the mobile phase to furnish solutions with final concentrations of 5-200 $\mu \mathrm{g} \mathrm{mL} \mathrm{m}^{-1}$ for naringin and hesperidin.

Sample preparation: The orange, grapefruit and tangerine juice were obtained by cutting the fruit in half and careful hand-squeezing to obtain the juice. The juice was filtered to remove pulp and seeds. The freshly squeezed juice was centrifuged at $13200 \mathrm{rpm}$ for $15 \mathrm{~min}$. The commercial fruit juice was directly centrifuged at $13200 \mathrm{rpm}$ for $15 \mathrm{~min}$. They were filtered with $0.45 \mu \mathrm{m}$ nylon membrane before injection.

Chromatographic conditions: The integrated high performance liquid chromatography system (LC 1100, HewlettPackard, USA) is equipped with a diode-array UV detector, a quarternary pump, a degasser, an autosampler, an injector with $20 \mu \mathrm{L}$ loop and a column oven. The separation was carried out using Zorbax Eclipse XDB C18 column (4.6 mm $\times 250$ $\mathrm{mm}, 5 \mu \mathrm{m})$.

The mobile phase was a acetonitrile:water:formic acid (21:78.8:0.2) aqueous solution at $\mathrm{pH}$ 2.5. The mobile phase was vacuum-filtered through a $0.45 \mu \mathrm{m}$ nylon filter and 


\begin{tabular}{cccccccccc}
\hline \multicolumn{10}{c}{ TABLE-1 } \\
\multicolumn{10}{c}{ LINEARITY STUDY RESULTS $(\mathrm{n}=6)$} \\
\hline Compound & $\begin{array}{c}\text { Retention } \\
\text { time }(\mathrm{min})\end{array}$ & $\begin{array}{c}\text { Range } \\
(\mathrm{mg} \mathrm{L})\end{array}$ & $\begin{array}{c}\text { Calibration curve } \\
(\mathrm{y}=\mathrm{mx} \pm \mathrm{n})\end{array}$ & $\begin{array}{c}\text { RSD }(\%) \\
(\mathrm{slope})\end{array}$ & $\mathrm{R}^{2}$ & $\begin{array}{c}\text { LOD } \\
\left(\mathrm{mg} \mathrm{L}^{-1}\right)\end{array}$ & $\begin{array}{c}\text { RSD } \\
(\%)\end{array}$ & $\begin{array}{c}\text { LOQ } \\
\left(\mathrm{mg} \mathrm{L}^{-1}\right)\end{array}$ & $\begin{array}{c}\text { RSD } \\
(\%)\end{array}$ \\
\hline Naringin & $12.60 \pm 0.07$ & $5-200$ & $\mathrm{y}=34.431 \mathrm{x}-6.1996$ & 3.03 & 0.9997 & 2.5 & 4.38 & 5 & 3.49 \\
Hesperidin & $14.55 \pm 0.08$ & $5-200$ & $\mathrm{y}=40.660 \mathrm{x}-23.0340$ & 2.30 & 0.9998 & 2.5 & 3.52 & 5 & 2.25 \\
\hline
\end{tabular}

degassed on-line by micro vacuum degasser. The chromatographic separation of these compounds performed at room temperature. Analysis was run at flow rate of $1 \mathrm{~mL} \mathrm{~min}^{-1}$ with 15 min run time. For the simultaneous detection of the hesperidin and naringin, the detector was set at $280 \mathrm{~nm}$. The injection volume was $20 \mu \mathrm{L}$.

Validation procedure: A full validation of assay consisting of linearity, lower limit of detection and quantitation (LOD and LOQ), intra-day and inter-day accuracy and precision of the method was performed according to the ICH description [13].

\section{RESULTS AND DISCUSSION}

The first step of the study was the optimization of the chromatographic conditions. The effect of acetonitrile:water ratio on the retention time of mixture was investigated. The ratio of the acetonitrile:water:formic acid was chosen as 21:78.8:0.2 (v:v:v) for optimum separation (Fig. 1).
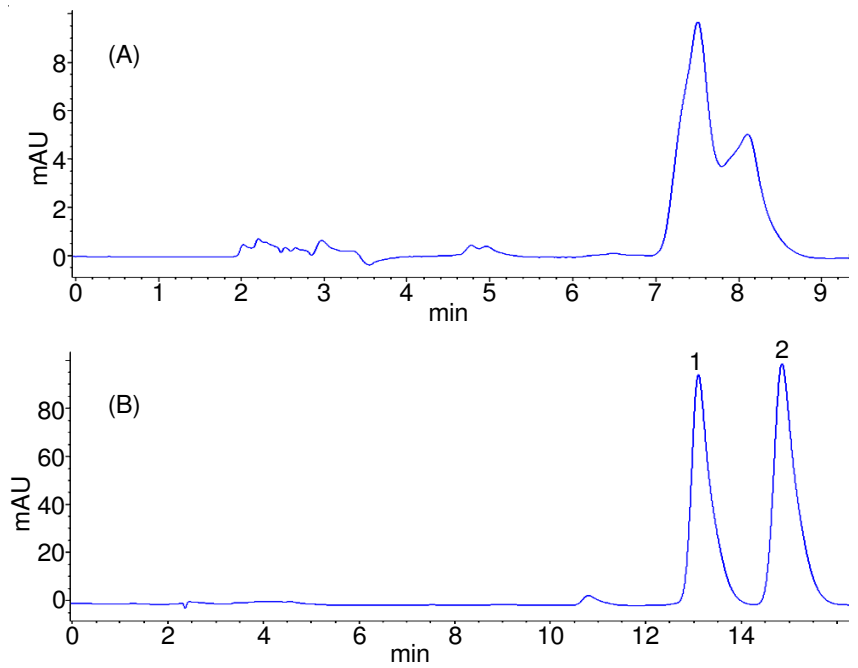

Fig. 1. A typical chromatogram of mixture. 1, naringin; 2, hesperidin (A) acetonitrile:water:formic acid (23:76.8:0.2) (B) acetonitrile: water: formic acid (21:78.8:0.2)

Quantifications of naringin and hesperidin were based on the calibration curves constructed under optimum conditions as the peak areas of analyzed substance. Linearity of the method was determined by performing injections at six different concentration levels in the linear range over 6 different days. Retention time (RT), linear range, $\mathrm{R}^{2}$, LOD and LOQ values are listed in Table-1.

Precision was expressed as the relative standard deviation of the control sample concentrations. Three different concentrations of standard solutions were analyzed six consecutive days and six times within the same day. Intra-assay (intraday) precisions were ranged from $1.75-3.62 \%$ for naringin and hesperidin. Inter-assay (inter-day) precisions values were in the range of 1.20 to $3.20 \%$ for them (Table-2).

\begin{tabular}{cccc}
\multicolumn{4}{c}{ TABLE-2 } \\
INTRA-DAY AND INTER-DAY PRECISION \\
RESULTS OF THE DEVELOPED METHOD $(\mathrm{n}=6)$ \\
\hline \multirow{2}{*}{ Compound } & Concentration & Inter-day & Intra-day \\
& & $($ RSD $\%)$ & $($ RSD $\%)$ \\
\hline \multirow{2}{*}{ Naringin } & 10 & 1.75 & 1.20 \\
& 80 & 1.88 & 1.54 \\
\multirow{2}{*}{ Hesperidin } & 160 & 2.72 & 1.95 \\
& 10 & 3.38 & 2.96 \\
& 160 & 3.62 & 3.07 \\
\hline
\end{tabular}

The accuracy of the proposed procedure was evaluated by means of recovery experiments. To demonstrate the accuracy of the method, a sample of fruit juice was analyzed before and after the addition of known amounts of naringin and hesperidin under study. The results obtained (Table-3) clearly demonstrate the accuracy of the method.

\begin{tabular}{|c|c|c|}
\hline \multicolumn{3}{|c|}{$\begin{array}{l}\text { TABLE-3 } \\
\text { RECOVERY OF NARINGIN AND HESPERIDIN } \\
\text { SPIKED FRUIT JUICE SAMPLES }(n=6)\end{array}$} \\
\hline Compound & Added $\left(\mathrm{mg} \mathrm{L}^{-1}\right)$ & Recovery (\%) \\
\hline \multirow{3}{*}{ Naringin } & 10 & 98.7 \\
\hline & 50 & 99.5 \\
\hline & 100 & 97.9 \\
\hline \multirow{3}{*}{ Hesperidin } & 10 & 96.8 \\
\hline & 50 & 97.7 \\
\hline & 100 & 98.5 \\
\hline
\end{tabular}

The optimized and validated method was applied for determination of naringin and hesperidin in natural and commercial citrus juices (Fig. 2). All samples were run in triplicate $(n=3)$. The obtained results were reported in Table-4.

\begin{tabular}{|c|c|c|}
\hline \multicolumn{3}{|c|}{$\begin{array}{c}\text { TABLE-4 } \\
\text { NARINGIN AND HESPERIDIN COMPOSITION OF } \\
\text { COMMERCIAL AND NATURAL FRUIT JUICE } \\
\text { SAMPLES BY HPLC METHOD }\end{array}$} \\
\hline & $\begin{array}{l}\text { Naringin } \\
\left(\mathrm{mg} \mathrm{L}^{-1}\right)\end{array}$ & $\begin{array}{l}\text { Hesperidin } \\
\left(\mathrm{mg} \mathrm{L}^{-1}\right)\end{array}$ \\
\hline cial orange juice & n.d. ${ }^{*}$ & $26.85 \pm 1.82$ \\
\hline orange juice & n.d. & $221.70 \pm 3.84$ \\
\hline ercial grapefruit ju ice & $56.75 \pm 2.01$ & n.d. \\
\hline 1 grapefruit juice & $323.07 \pm 3.45$ & $5.53 \pm 0.87$ \\
\hline ercial tangerine juice & n.d. & $12.13 \pm 1.10$ \\
\hline 1 tangerine juice & $5.39 \pm 0.73$ & $142.46 \pm 2.62$ \\
\hline
\end{tabular}

Results are expressed as mean $\pm \mathrm{SD}$ ( standard deviation) $(\mathrm{n}=3)$, " $n$.d.not detected

\section{Conclusion}

A rapid, basic and reliable HPLC method has been developed and validated for the determination of hesperidin and naringin in natural and commercial citrus juices. Compared to the other reported ones, the developed method offers fast separation and simple sample preparation needed only centrifugation and filtration before injection. 

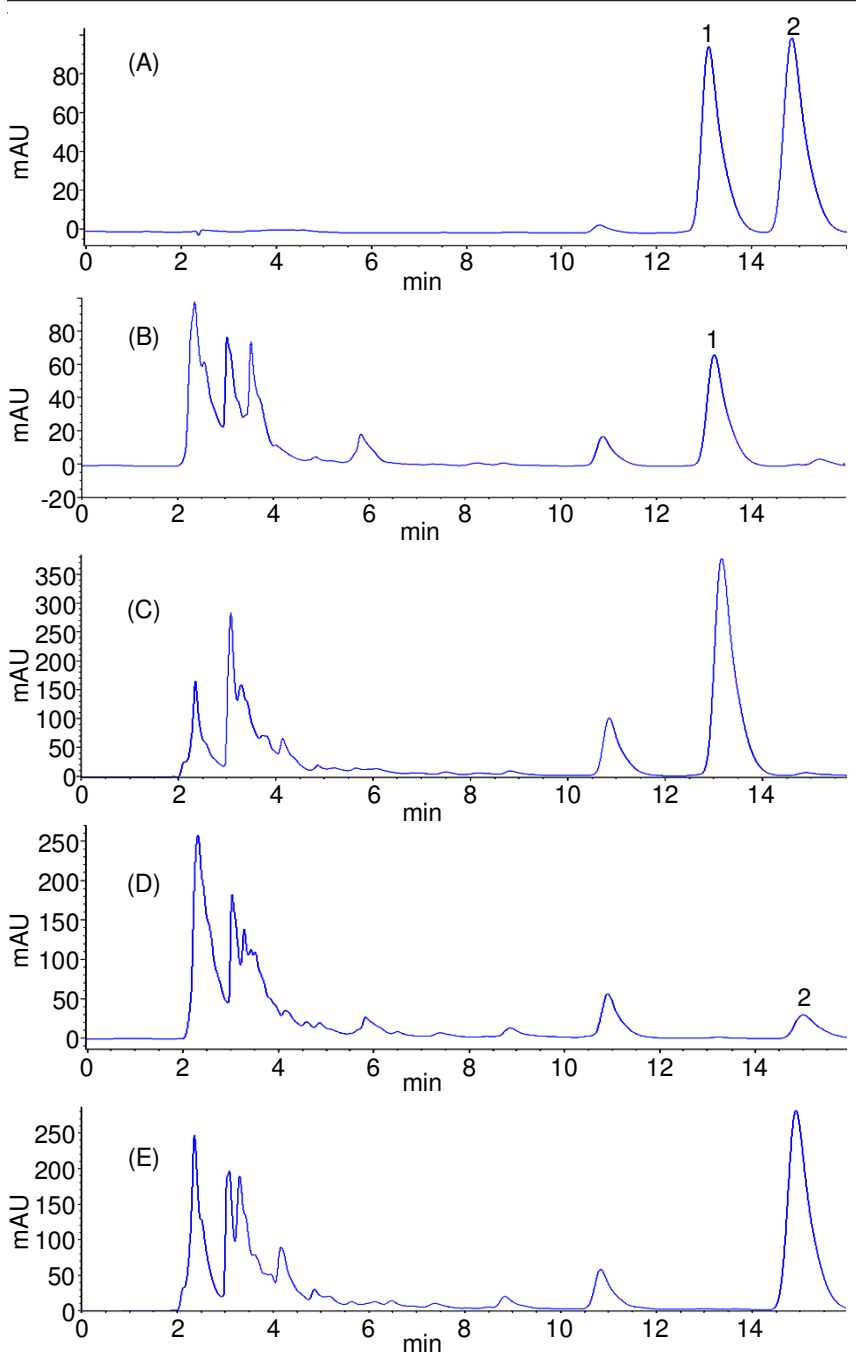

Fig. 2. (A) Chromatogram of standards of analyte at $280 \mathrm{~nm}$. The peaks correspond to: 1 , naringin; 2 , hesperidin; (B) Chromatogram of commercial grapefruit juice (C) Chromatogram of freshly squeezed grapefruit juice (D) Chromatogram of commercial orange juice (E) Chromatogram of freshly squeezed orange juice

Naringin and hesperidin are the most important flavonoids in citrus fruits. The main compound in grapefruit juice is naringin.
The main compound in orange juice and tangerine juice is hesperidin. Commercial orange juices and tangerine juices contain lower amount of hesperidin compared with natural orange juices. Commercial grapefruit juices contain lower amount of naringin compared with natural grapefruit juices. According to this research the citrus juices should be consumed freshly.

\section{REFERENCES}

1. Y. Lu, C. Zhang, P. Bucheli and D. Wei, Plant Foods Hum. Nutr., 61, 55 (2006); https://doi.org/10.1007/s11130-006-0014-8.

2. F.I. Kanaze, C. Gabrieli, E. Kokkalou, M. Georgarakis and I. Niopas, J. Pharm. Biomed. Anal., 33, 243 (2003); https://doi.org/10.1016/S0731-7085(03)00289-9.

3. E. Tripoli, M.L. Guardia, S. Giammanco, D.D. Majo and M. Giammanco, Food Chem., 104, 466 (2007); https://doi.org/10.1016/j.foodchem.2006.11.054.

4. M. Delourdesmatabilbao, C. Andreslacueva, R. Lamuelaraventos and O. Jauregui, Food Chem., 101, 1742 (2007); https://doi.org/10.1016/j.foodchem.2006.01.032.

5. S. Ejaz, A. Ejaz, K. Matsuda and C.W. Lim, J. Sci. Food Agric., 86, 339 (2006); https://doi.org/10.1002/jsfa.2396.

6. M.A. Anagnostopoulou, P. Kefalas, E. Kokkalou, A.N. Assimopoulou and V.P. Papageorgiou, Biomed. Chromatogr., 19, 138 (2005); https://doi.org/10.1002/bmc.430.

7. D. He, Y. Shan, Y. Wu, G. Liu, B. Chen and S. Yao, Food Chem., 127, 880 (2011); https://doi.org/10.1016/j.foodchem.2010.12.109.

8. H. Kelebek, S. Selli, A. Canbas and T. Cabaroglu, Microchem. J., 91, 187 (2009);

https://doi.org/10.1016/j.microc.2008.10.008.

9. I.A. Ribeiro and M.H.L. Ribeiro, Food Control, 19, 432 (2008); https://doi.org/10.1016/j.foodcont.2007.05.007.

10. W.V. De-Castro, S. Mertens-Talcott, A. Rubner, V. Butterweck and H. Derendorf, J. Agric. Food Chem., 54, 249 (2006); https://doi.org/10.1021/jf0516944.

11. T. Wu, Y. Guan and J. Ye, Food Chem., 100, 1573 (2007); https://doi.org/10.1016/j.foodchem.2005.12.042.

12. D. Satinsky, K. Jagerova, L. Havlikova and P. Solich, Food Anal. Methods, 6, 1353 (2013); https://doi.org/10.1007/s12161-012-9551-y.

13. ICH Steering Committee, Validation of Analytical Procedures, Text and Methodology, Q2(R1), 1 (2005). 